\title{
A fault tolerant control approach for descriptor systems
}

\section{Niemann, Hans Henrik}

\section{Published in:}

Proceedings of the 2005 American Control Conference, 2005.

Link to article, DOI:

10.1109/ACC.2005.1470300

Publication date:

2005

Document Version

Publisher's PDF, also known as Version of record

Link back to DTU Orbit

Citation (APA):

Niemann, H. H. (2005). A fault tolerant control approach for descriptor systems. In Proceedings of the 2005 American Control Conference, 2005. (Vol. 3). IEEE. https://doi.org/10.1109/ACC.2005.1470300

\section{General rights}

Copyright and moral rights for the publications made accessible in the public portal are retained by the authors and/or other copyright owners and it is a condition of accessing publications that users recognise and abide by the legal requirements associated with these rights.

- Users may download and print one copy of any publication from the public portal for the purpose of private study or research.

- You may not further distribute the material or use it for any profit-making activity or commercial gain

- You may freely distribute the URL identifying the publication in the public portal

If you believe that this document breaches copyright please contact us providing details, and we will remove access to the work immediately and investigate your claim 


\title{
A Fault Tolerant Control Approach for Descriptor Systems
}

\author{
Henrik Niemann
}

\begin{abstract}
Fault Tolerant Control (FTC) of descriptor systems is considered in this paper. A general FTC architecture for descriptor systems is proposed.
\end{abstract}

\section{INTRODUCTION}

There are many trends in the development of control systems. The most important trend is the growing complexity of the control systems. According to elementary reliability theory there is at least one challenge in this connection: Growing complexity increases the probability of critical faults occurring in the system. This motivates the interest in the design of fault tolerant control systems, where the objective is to disallow one or several faults to develop into an overall system failure.

This has resulted in an increasing research in the area of reliable and fault tolerant control of dynamic systems. A good introduction to the area of fault tolerant control can be found in Blanke et.al. [1], and the references herein. A number of theoretic results has been presented in this area in [6], [8].

These results are derived for regular systems. However, not all systems are regular. Physical constraints or static relations can be included in the model, which lead to descriptor systems. The main result in this paper is to generalize the FTC architecture proposed in [6] in such a way that fault tolerant control for descriptor systems can be handled in the same framework.

\section{System SetuP}

Consider the following generalized nominal system:

$$
\Sigma_{P}:\left\{\begin{aligned}
E \dot{x} & =A x+B_{w} w+B_{d} d+B_{u} u \\
z & =C_{z} x+D_{z w} w+D_{z d} d+D_{z u} u \\
e & =C_{e} x+D_{e w} w+D_{e d} d+D_{z u} u \\
y & =C_{y} x+D_{y w} w+D_{y f} d+D_{y u} u
\end{aligned}\right.
$$

where $x \in \mathcal{R}^{n}$ is the descriptor variable, $d \in \mathcal{R}^{r}$ is a disturbance signal vector, $u \in \mathcal{R}^{m}$ the control input vector, $e \in \mathcal{R}^{q}$ is the external output vector to be controlled, $y \in \mathcal{R}^{p}$ is the measurement vector, $w \in \mathcal{R}^{k_{w}}$ and $z \in \mathcal{R}^{k_{z}}$ are the external input and output vectors. The connection between $z$ and $w$ is given by $w=\theta z$ where $\theta$ represents the parametric faults in the system. Closing the loop from $w$ to $z$ in $\Sigma_{P}$ by using $\theta$, we get

$$
\Sigma_{P, \theta}=\mathcal{F}_{u}\left(\Sigma_{P}, \theta\right)
$$

The matrix $E$ may be rank deficient, i.e. $\operatorname{rank}(E)=k \leq n$. The system $\Sigma_{P}$ is regular if $\operatorname{det}(s E-A) \neq 0$. For a regular

H. Niemann is with Ørsted•DTU, Automation, Technical University of Denmark, Building 326, DK-2800 Kgs. Lyngby, Denmark. E-mail: hhndoersted. dtu.dk
$(E, A)$, the system $\Sigma_{P}$ has a unique solution for any initial condition. The finite eigenvalues of the pencil $s E-A$ are called the finite dynamic modes. Suppose that $(E, A)$ is regular and $l=\operatorname{deg} \operatorname{det}(s E-A)$. Then $(E, A)$ has $l$ finite dynamic modes, $(n-k)$ non-dynamic modes and $(k-l)$ impulsive modes. If $(E, A)$ does not have any dynamic modes in $\operatorname{Re}[s] \geq 0$, the system is stable. Further, $(E, A)$ is admissible if $(E, A)$ is regular, impulse-free and stable.

It will be assumed in the rest of this paper that the $\Sigma_{P}$ given by (1) satisfy, [9]:

1) $(E, A)$ is regular

2) $\left(E, A, B_{u}\right)$ is finite dynamics stabilizable and impulse controllable, $\operatorname{rank}\left[s E-A B_{u}\right]=n, \forall s$, s.t. $\operatorname{Re}[s] \geq 0$, $\operatorname{Im} E+\operatorname{ImAkerE}+\operatorname{Im} B_{u}=\mathcal{R}^{n}$

3) $\left(E, A, C_{y}\right)$ is impulse observable and finite dynamics detectable, $\operatorname{rank}\left[s E^{T}-A^{T} C_{y}^{T}\right]=n, \forall s$, s.t. $\operatorname{Re}[s] \geq 0$, $\operatorname{Im} E^{T}+\operatorname{Im} A^{T} k e r E^{T}+\operatorname{Im} C_{y}^{T}=R^{n}$

Let the system be controlled by a stabilizing feedback controller given by:

$$
\Sigma_{K}:\{u=K(s) y
$$

\section{THE YJBK PARAMETERIZATION}

Before describing a general FTC architecture for descriptor systems, the YJBK parameterization for descriptor systems is shortly introduced.

Let a coprime factorization of the system $G_{y u}(s)$ from (1) and a stabilizing controller $K(s)$ from (3) be given by:

$$
\begin{array}{ll}
G_{y u} & =N M^{-1}=\tilde{M}^{-1} \tilde{N}, \quad N, M, \tilde{N}, \tilde{M} \in \mathcal{R} \mathcal{H}_{\infty} \\
K & =U V^{-1}=\tilde{V}^{-1} \tilde{U}, \quad U, V, \tilde{U}, \tilde{V} \in \mathcal{R} \mathcal{H}_{\infty}
\end{array}
$$

where the eight matrices in (4) must satisfy the double Bezout equation given in [9].

Let the controller $K(s)$ be an observer based feedback controller given by:

$$
K(s)=\left\{E,\left[\begin{array}{c|c}
A+B_{u} F+L C_{y}+L D_{y u} F & -L \\
\hline F & 0
\end{array}\right]\right\}
$$

where $F$ and $L$ are selected such that $E, A+B_{u} F$ and $E, A+$ $L C_{y}$ are both admissible. One possible way to construct the eight stable coprime matrices in (4) is then:

$$
\begin{aligned}
\left(\begin{array}{cc}
M & U \\
N & V
\end{array}\right) & =\left\{E,\left(\begin{array}{c|cc}
A+B_{u} F & B_{u} & -L \\
\hline F & I & 0 \\
C_{y F} & D_{y u} & I
\end{array}\right)\right\} \\
\left(\begin{array}{cc}
\tilde{V} & -\tilde{U} \\
-\tilde{N} & \tilde{M}
\end{array}\right) & =\left\{E,\left(\begin{array}{c|cc}
A+L C_{y} & -B_{u L} & L \\
\hline F & I & 0 \\
C_{y} & -D_{y u} & I
\end{array}\right)\right\}
\end{aligned}
$$

with $C_{y F}=C_{y}+D_{y u} F$ and $B_{u L}=B_{u}+L D_{y u}$. 
Based on the above coprime factorization of the system $G_{y u}(s)$ and the controller $K(s)$, a parameterization of all controllers stabilizing the system in terms of a stable parameter $Q(s)$ is given by [3]:

$$
K(Q)=(U+M Q)(V+N Q)^{-1}, Q \in \mathcal{R} \mathcal{H}_{\infty}
$$

Using the Bezout equation, the controller given by (7) can be realized as an LFT in the parameter $Q$,

$$
K(Q)=\mathcal{F}_{l}\left(\left(\begin{array}{cc}
U V^{-1} & \tilde{V}^{-1} \\
V^{-1} & -V^{-1} N
\end{array}\right), Q\right)=\mathcal{F}_{l}\left(J_{K}, Q\right)
$$

\section{FAUlt Diagnosis FOR DESCRIPTOR SYSTEMS}

It has been shown in [2] that it is possible to parameterize all residual generators by using the YJBK parameterization. The same result is valid for descriptor systems, see [4]. All residual signals $r_{q}$ for the descriptor system (1) can be described by, [4]

$$
r_{q}=Q_{\mathrm{FDI}}(\tilde{M} y-\tilde{N} u)=Q_{\mathrm{FDI}} r
$$

where $Q_{\text {FDI }}$ is a stable and proper filter of suitable order. $Q_{\text {FDI }}$ need to be designed such that the residual signal/vector $r_{q}$ satisfy the conditions for fault detection and fault isolation, see e.g. [7]. The residual signal in (9) is given by

$$
r_{q}=Q_{\mathrm{FDI}} \tilde{M}\left(G_{y d}(\theta) d+G_{y w} \theta\left(I-G_{z w} \theta\right)^{-1} G_{z u} u\right)
$$

\section{Fault Tolerant Controller Architecture}

A fault tolerant controller mainly consists of two parts, a fault diagnosis (FDI) part and a controller reconfiguration (CR) part. Based on the output from a decision block, the controller is reconfigured by using the YJBK parameter. This means that the CR part of the feedback controller is a modification of the existing controller. Thus, a controller change when a fault appears in the system is not a complete shift to another controller, but only a modification of the existing controller by adding a correction signal in the nominal controller. The reconfiguration can be derived in different ways. It can be a direct redesign, a selection between a number of pre-designed controllers etc.

All together, the complete architecture is shown in Fig. 1. Here $Q_{\mathrm{FDI}}$ is the YJBK parameter used in connection with fault diagnosis and $Q_{\mathrm{RC}}$ is the YJBK parameter used in connection with controller reconfiguration.

The design of the reconfiguration part of the fault tolerant controller can be derived by considering the closed loop transfer function from external input $d$ to external output $e$. The closed loop transfer function is given by:

$$
e=\mathcal{F}_{l}\left(P, Q_{\mathrm{CR}}\right) d=T_{e d}(s) d
$$

where $P$ is the transfer function between the two inputs $(d, \eta)$ and the two outputs $(e, r)$, see Fig. 1 .

The design of the $Q_{\mathrm{CR}}$ can be considered either as a stabilization problem or as a performance design problem. Stabilizing the closed loop system by using $Q_{\mathrm{CR}}$ is obtained if and only if

$$
\left(I-Q_{\mathrm{CR}} P_{r r}(\theta)\right)^{-1}
$$

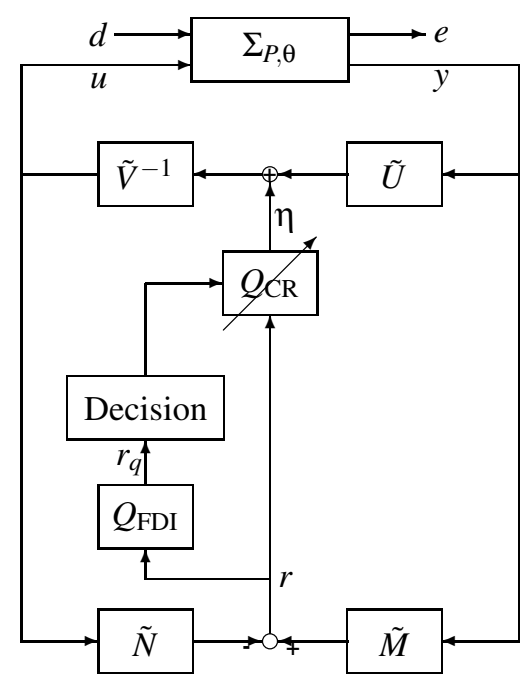

Fig. 1. A fault tolerant controller architecture.

is stable. This problem is again a controller design problem for descriptor systems. In the performance design problem, $Q_{\mathrm{CR}}$ needs to be designed such that the closed-loop system is stable, i.e. (12) is satisfied, and a suitable norm of the closed loop system $T_{e d}(s)$ is minimized.

Note that the same FTC architecture can also be applied when an active FDI approach is used for fault diagnosis, see [5].

\section{REFERENCES}

[1] M. Blanke, C.W. Frei, F. Kraus, R.J. Patton, and M. Staroswiecki. What is fault-tolerant control? In Preprints of 4th IFAC Symposium on Fault Detection Supervision ans Safety for Technical Processes, SAFEPROCESS'2000, pages 40-51, Budapest, Hungary, 2000.

[2] P.M. Frank and X. Ding. Frequency domain approach to optimally robust residual generation and evaluation for model-based fault diagnosis. Automatica, 30:789-804, 1994.

[3] W.Q. Lie, W.Y. Yan, and K.L. Teo. A frequency domain approach to control of singular systems. IEEE Transactions on Automatic Control, 42(6):885-889, 1997.

[4] B. Marx, D. Koenig, and D. Georges. Robust fault diagnosis for descriptor systems - A coprime factorization approach. In Preprints of 5th IFAC Symposium on Fault Detection Supervision ans Safety for Technical Processes, SAFEPROCESS'2003, pages 507-512, Washington D.C, USA, 2003.

[5] H.H. Niemann. Fault tolerant control based on active fault diagnosis. In Proceedings of the American Control Conference, pages 000-000, Portland, Oregon, USA, 2005.

[6] H.H. Niemann and J. Stoustrup. Reliable control using the primary and dual Youla parameterization. In Proceedings of the 41st IEEE Conference on Decision and Control, pages 4353-4358, Las Vegas, NV, USA, 2002.

[7] A. Saberi, A.A. Stoorvogel, P. Sannuti, and H.H. Niemann. Fundamental problems in fault detection and identification. International Journal of Robust and Nonlinear Control, 10(14):1209-1236, 2000.

[8] J. Stoustrup and H.H. Niemann. Fault tolerant feedback control using the youla parameterization. In Proceedings of the 6th European Control Conference, pages 1970-1974, Porto, Portugal, September 2001.

[9] K. Takaba, N. Morihira, and T. Katayama. $H_{\infty}$ control for descriptor systems - A J-spectral factorization approach. In Proceedings of the 33rd Conference on Decision and Control, pages 2251-2256, Lake Buena Vista, Fl, USA, 1994. 